\title{
Halogen Bonding in the framework of classical force
}

\author{
fields: the case of chlorine
}

\author{
Davide Franchini,[a] Federico Dapiaggi,[a] Stefano Pieraccini, *[a, b] Alessandra Forni, *[b]
} and Maurizio Sironi* $[a, b]$

[a] Dr. D. Franchini, Dr. F. Dapiaggi, Dr. S. Pieraccini, Prof. Dr. M. Sironi

Dipartimento di Chimica and INSTM UdR, Università degli Studi di Milano

Via Golgi 19, 20133, Milano (Italy)

E-mail: stefano.pieraccini@unimi.it, maurizio.sironi@unimi.it

[b] Dr. A. Forni, Dr. S. Pieraccini, Prof. Dr. M. Sironi

CNR-ISTM (Istituto di Scienze e Tecnologie Molecolari del CNR) and INSTM UdR

Via Golgi 19, 20133, Milano (Italy)

E-mail: alessandra.forni@istm.cnr.it

\begin{abstract}
Halogen bonding is nowadays a consolidated tool in chemistry. Only recently, the importance of halogen bonding has been demonstrated also in biological systems, owing to the presence of halogens in drugs.This interaction is due to the anisotropy of the electron density around the halogen that leads to the formation of the ' $\sigma$-hole', which is responsible for the interaction with a nucleophile site. Unfortunately, classical force fields used in the study of ligand-receptor systems
\end{abstract}


are not able to describe the ' $\sigma$-hole'. Here, we propose a pseudo-atom based methodology able to correctly describe halogen bonding involving chlorine using classical force field.

\section{INTRODUCTION}

Halogen bonding $(\mathrm{XB})$ is a highly directional, non-covalent interaction established between a halogen atom (X) covalently bonded to a donor group (D) and a nucleophilic site A, the halogen bonding acceptor, according to the scheme $\mathrm{D}-\mathrm{X} \cdots \mathrm{A}$. The donor moiety $\mathrm{D}$ can range from another halogen atom to an organic or inorganic group, whereas the nucleophilic acceptor site is most often a lone pair on a heteroatom such as nitrogen, oxygen or sulfur. At first glance, the formation of halogen bonding appears a rather unexpected phenomenon as it involves the interaction between an electronegative, supposed spherical, species and a Lewis base. Actually, the electron density around a covalently bonded halogen atom is not uniformly distributed, exhibiting a depletion along the $\mathrm{D}-\mathrm{X}$ bond axis in the region outward the bond itself, that is compensated by a relative increase in a belt around the bond axis. A simple and intuitive model to explain the origin of such anisotropy has been developed by Politzer and coworkers. ${ }^{1}$ Compared to an isolated halogen atom, which has spherical symmetry and 5/3 average $p$ electron population in each direction, the electronic structure of a halogen atom covalently bonded to another atom along the $z$ axis can be approximately written as $\mathrm{s}^{2} \mathrm{p}_{\mathrm{x}}{ }^{2} \mathrm{p}_{\mathrm{y}}{ }^{2} \mathrm{p}_{\mathrm{z}}{ }^{1}$. The region of lower electron density along the extension of the $\mathrm{D}-\mathrm{X}$ bond, denoted as $\sigma$-hole, ${ }^{2}$ generally reflects in a positive electrostatic potential which is responsible for the interaction with a nucleophile site. The size and depth of the $\sigma$-hole depend on the electron withdrawing capability of the donor group and on the nature of the halogen atom. A good correlation has been observed between the values of the electrostatic potential (ESP) on the $\sigma$-hole and the strength of halogen bond, ${ }^{3}$ 
although the electrostatic contribution is not the only energetic term giving rise to this interaction. Depending on the nature of the halogen and of the donor and acceptor groups, also dispersive forces can play a significant role.,

The persistent view of halogens as electronegative species has long prevented researchers to think to bonded halogens as responsible for even strong interactions with nucleophilic sites. Only in the past two decades, differently for the more explored hydrogen bonding (HB), the potential of $\mathrm{XB}$ in directing assembly phenomena has become to be explored. Thanks to its strength, directionality and intrinsic tunability, the latter resulting from the possibility to span the four halogen atoms, halogen bonding has found a plethora of possible applications in the most diversified fields of chemistry and biology, going from photoluminescent materials ${ }^{6}$ to nonlinear optics, ${ }^{7}$ supramolecular chemistry ${ }^{8,9}$ and drug design. ${ }^{10-14}$ In addition, XB is ubiquitously present in biological systems, as pointed out by protein data bank (PDB) analysis. ${ }^{18}$ For a long time, halogenated drug molecules were predominantly adopted due to their increased metabolic stability and membrane permeability conferred by halogen atoms. It has been also shown that $\mathrm{XB}$ can compete with $\mathrm{HB}$ in stabilizing brominated DNA junctions. ${ }^{10,15}$ In recent years it has been observed that halogen atoms can increase the drug-target affinity through $\mathrm{XB}$, thus increasing drug activity of several orders of magnitude with respect to analogous nonhalogenated moieties. ${ }^{11,16,17}$ For these reasons, halogen bonding has been the subject of numerous computational studies on both molecular and macromolecular systems. At molecular level, highly correlated methods and density functional theory (DFT) have been largely used to study this interaction in gas-phase ${ }^{19-22}$ and in solution using continuum models of the solvent. ${ }^{23-25}$ Quantum mechanics/molecular mechanics $(\mathrm{QM} / \mathrm{MM})$ methods have been used to describe the interaction of halogenated molecules with proteins. ${ }^{18}$ In this context, many efforts have been 


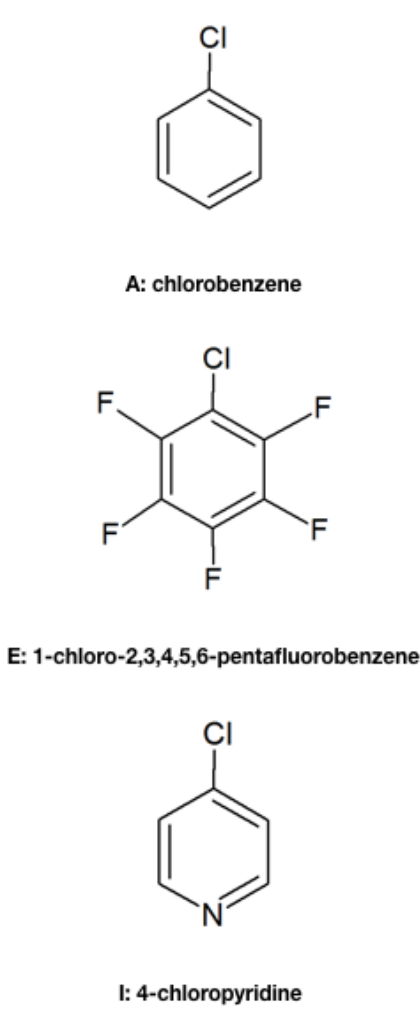

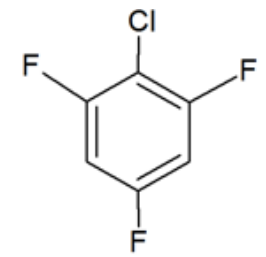

B: 1-chloro-4-fluorobenzene<smiles>Cc1ccc(Cl)cc1</smiles>

F: 1-chloro-4-metilbenzene<smiles>Clc1cncnc1</smiles>

L: 4-chloropyrimidine
C: 1-chloro-2,4,6-trifluorobenzene<smiles>Cc1cc(C)c(Cl)c(C)c1</smiles>

G: 1-chloro-2,4,6-trimetilbenzene<smiles>Brc1ccccc1</smiles>

M: bromobenzene<smiles>Fc1cc(F)cc(Cl)c1</smiles>

D: 1-chloro-3,5-difluorobenzene<smiles>COc1ccc(Cl)cc1</smiles><smiles>CC(=O)NC(C)C(N)=O</smiles>

Capped alanine, halogen bond acceptor

Figure 1. Chlorinated $(\mathrm{A} \div \mathrm{L})$ or brominated $(\mathrm{M})$ model systems chosen to study halogen bond with the carbonyl oxygen of the capped alanine through the Pseudo-atom(s) strategy.

\section{MATERIALS AND METHODS}

The structures of eleven halogenated molecules complexed by capped alanine (see Figure 1), taken as benchmark in the MM energy minimization, were obtained by quantum mechanical geometry optimizations using the software Gaussian $09 .{ }^{46}$ In particular, for all the complexes DFT (BSSE free) calculations were performed by using the M06-2X ${ }^{44}$ functional, an hybrid meta-GGA functional that is highly recommended to study halogen bonding and other noncovalent interactions; ${ }^{25}$ the $6-311++\mathrm{G}(\mathrm{d}, \mathrm{p})$ basis set has been used for all atoms in the complexes.

The partial atomic charges for the ligands were derived exploiting the RESP procedure, as implemented in AMBER11, on the ESP as obtained by RHF/6-31G(d,p) Gaussian09 
calculations. To evaluate the goodness of the RESP fitting to the RHF electrostatic potential, the relative root mean square error (RRMS) has been monitored. Two different dispositions of pseudo-atoms have been then tested (see Figure 2): in the first one (' $1 \mathrm{~Pa}$ ' disposition, A), a single pseudo-atom $(\mathrm{Pa})$ has been added along the extension of the $\mathrm{D}-\mathrm{X}$ bond, pointing towards the $\mathrm{XB}$ acceptor, and several $\mathrm{X}-\mathrm{Pa}$ distances have been tested as described in the Results section; in the second one (' $5 \mathrm{~Pa}$ ' disposition, $\mathrm{B}$ ), five $\mathrm{Pa}$ 's were added to the halogenated ligands: one in the same position as in ' $1 \mathrm{~Pa}$ ' and the other four along two directions, orthogonal each other and perpendicular to the $\mathrm{D}-\mathrm{X}$ bond, so that each of these four Pa's is the vertex of a square with the chlorine atom in the center. Also in this case several X-Pa distances have been tested. To parametrize the halogenated molecules the $\mathrm{GAFF}^{45,47}$ force fields have been adopted, while for the capped alanine the ff99SBildn force field has been employed. ${ }^{48}$
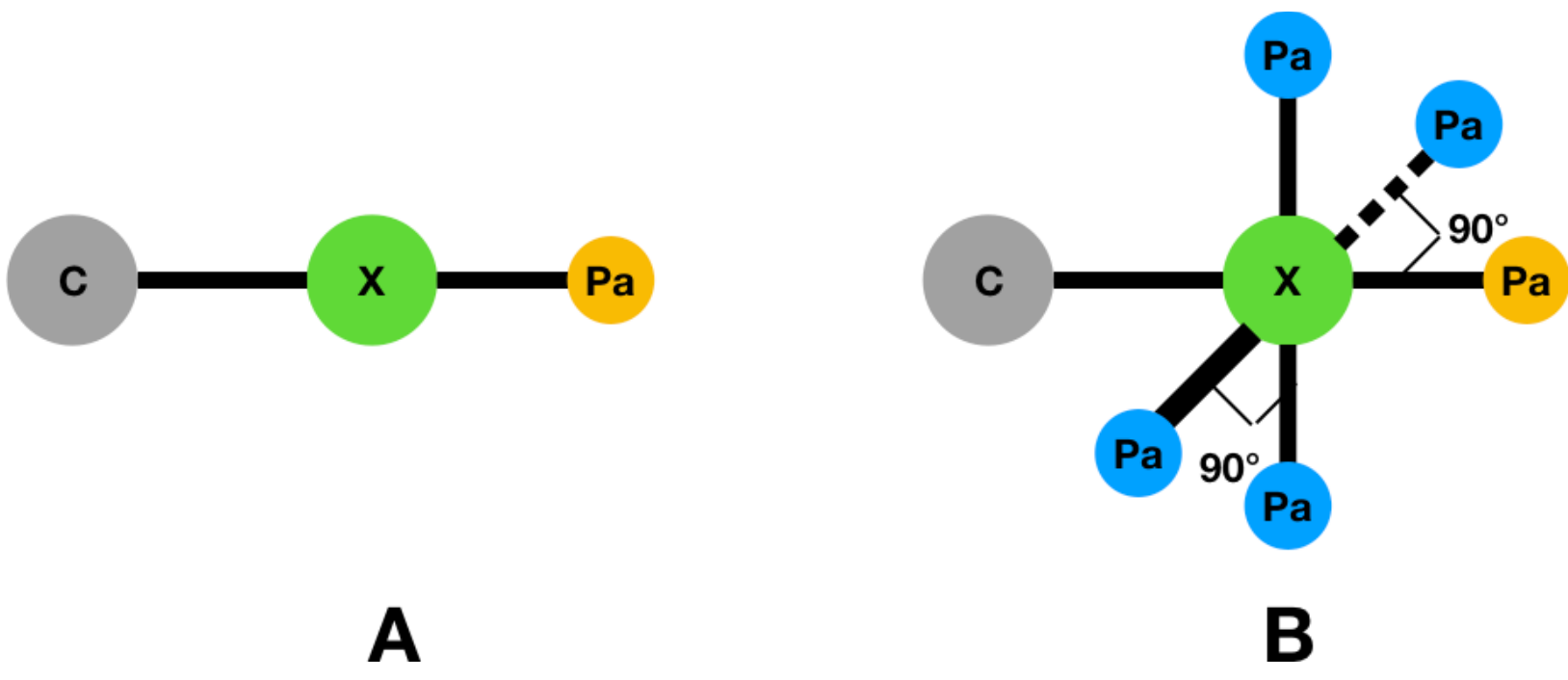

Figure 2. Dispositions of pseudo-atoms adopted to describe the anisotropy of electron density around the halogen atoms (X, Pa and $\mathrm{C}$ stand for halogen, pseudo-atom and carbon, respectively). A: ' $1 \mathrm{~Pa}$ ' disposition where one $\mathrm{Pa}$ is used to simulate the charge of the $\sigma$-hole. $\mathrm{B}$ : 
'5Pa' disposition, where one $\mathrm{Pa}$ (in yellow) is used to simulate the charge of the $\sigma$-hole and the other four surrounding the halogen are used to enhance the negative belt.

In order to better reproduce the DFT geometrical parameters (interaction distances and angles) of halogen bonding, different values of the van der Waals radius parameter for the chlorine atom have been tested in all the analyzed systems, as described in the Results section, while the well energy depth (the energy minimum for the vdW interaction) has been kept fixed to $0.265 \mathrm{kcal}$ $\mathrm{mol}^{-1}$. Such tests showed that a lowering of the chlorine vdW radius parameter improves the description of the $\mathrm{XB}$ geometrical parameters and it is also consistent with the variation of the non-bonded parameters for bromine and iodine passing from the original Amber force field ${ }^{40}$ to the more recent one.

The ACPYPE utility has been used to convert the AMBER input files into the Gromacs ones. MM energy minimizations were then performed with Gromacs 5.0.7 $7^{42}$ package on all complexes either in the native form and after pseudo-atoms insertion for both $\mathrm{Pa}(\mathrm{s})$ dispositions. We adopted 10000 steps of steepest descendent minimization, with 10 steps of conjugate gradient minimization for every step of steepest minimization.

To compare the $\mathrm{XB}$ geometrical parameters as obtained from classical energy minimization (em) using the pseudo-atom(s) and DFT approaches, the percentage errors $\left(S_{\text {distance }}\right.$ and $\left.S_{\text {angle }}\right)$, as defined in equations (1) and (2), have been used.

$$
\begin{aligned}
& S_{\text {distance }}=\frac{\left|d_{e m}-d_{D F T}\right|}{d_{D F T}} \\
& S_{\text {angle }}=\frac{\left|a n g_{e m}-a n g_{D F T}\right|}{a n g_{D F T}}
\end{aligned}
$$


where $d_{e m}$ and ang $_{e m}$ are the interaction distances and angles, respectively, as obtained from the classical approach, while $d_{D F T}$ and $a g_{D F T}$ are the corresponding parameters as obtained from M06-2X/6-311++G(d,p) geometry optimization.

\section{RESULTS AND DISCUSSION}

Halogen bonding established in ten chlorinated model systems with capped alanine (see Figure 1) has been studied by means of Molecular Mechanics energy minimization with the purpose of developing a new strategy to be used in classical force fields methods, owing to the failure of the previously reported pseudo-atom methods ${ }^{36-38}$ in describing chlorine-based XB. The new approach is based on the use of a set of pseudo-atoms, Pa's, in place of a single one as previously proposed. ${ }^{36-38}$ The model systems were properly chosen to simulate halogenated ligands in protein-ligand complexes, while the capped alanine has been used because it is a typical XB acceptor in protein-ligand systems, as underlined by a PBD survey. ${ }^{18}$ As benchmark for testing our model systems, the BSSE-free M06-2X/6-311++G(d,p) optimized X‥O distances and C$\mathrm{X} \cdots \mathrm{O}$ angles have been used. Several Pa's models as obtained by varying the number of $\mathrm{Pa}$ 's and their dispositions, their distances from the halogen and the $\mathrm{vdW}$ radius of the halogen have been tested. The case of no Pa has been as well taken into account.

The disposition of the Pa's around the halogen is shown in Figure 2. While in the previously proposed ' $1 \mathrm{~Pa}$ ' strategy (Figure 2A) a single Pa was used to reproduce the positive charge of the $\sigma$-hole, in the present '5Pa' scheme (Figure 2B) four additional Pa's are added to describe the negative belt around the halogen atom. As it can be observed from the electrostatic potential maps shown in Figure 3, the full set of extra-point charges allows to reproduce the anisotropy of 
the quantum mechanical ESP by using classical methods, in contrast to the case in which no pseudo-atom has been introduced.

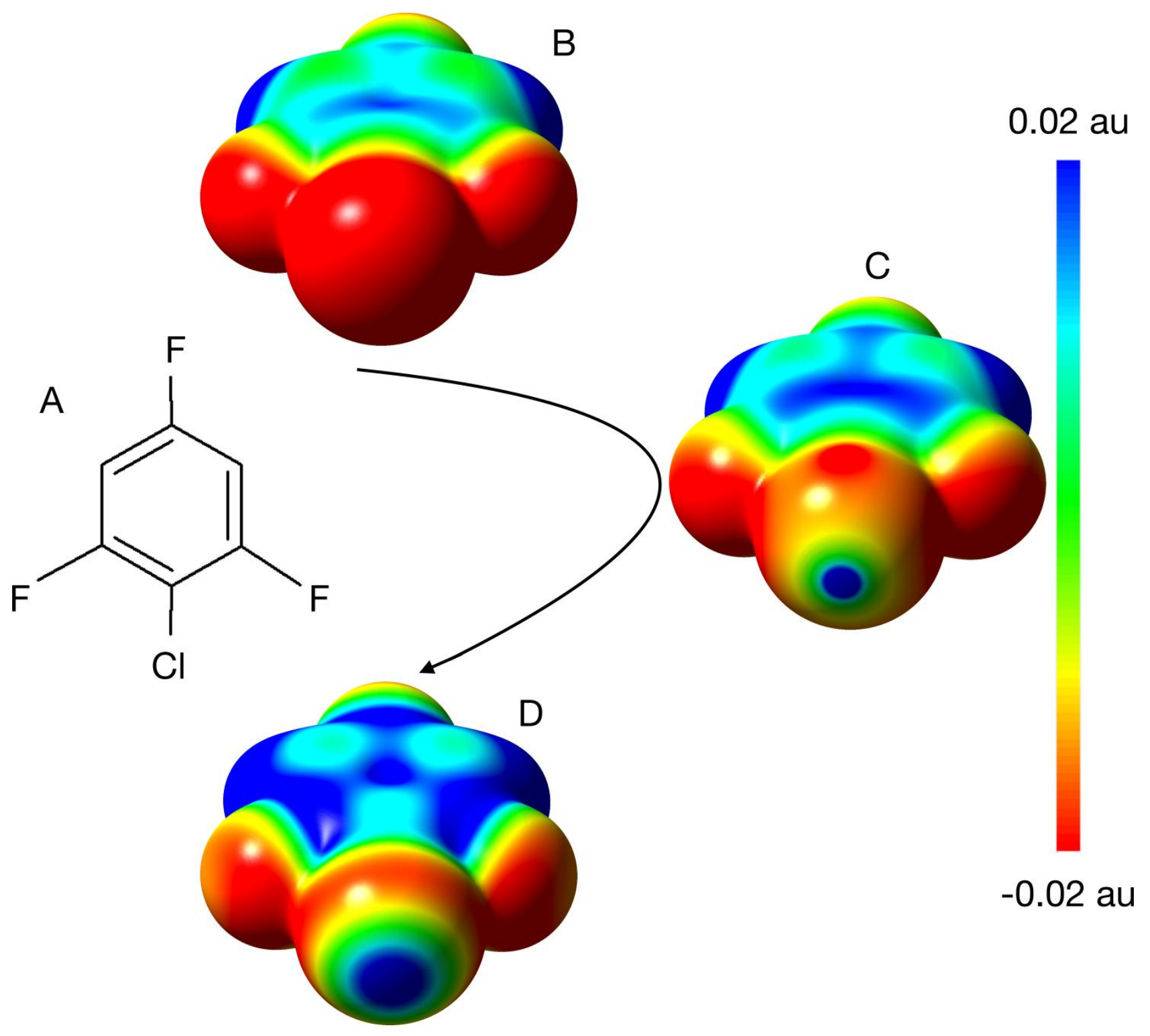

Figure 3. Electrostatic potential mapped onto the electron density surface $\left(0.002\right.$ electrons $\left.a^{-3}\right)$ of 1-chloro-2,4,6-trifluorobenzene (A), calculated at RHF/6-31G(d) level of theory (D) or using the RESP procedure without pseudo-atom(s) (B) and after five (C) pseudo-atoms addition at 1.8 $\AA$ from the chlorine atom. 
It is to be noted that the MM minimization, while providing positive charge, as expected, for the ' $\sigma$-hole' $\mathrm{Pa}$, resulted in either negative charges for the 'lateral' $\mathrm{Pa}$ 's in all chlorinated derivatives or positive charges for bromobenzene, which was included in our investigation as a check of our procedure (see Tables 3 and 4). This observation is in good agreement with the results of a charge density investigation by Espinosa et al., ${ }^{50}$ who explored the differences between the chlorine and bromine $\sigma$-hole "architectures" based on analysis of the Laplacian of electron density, $\nabla^{2} \rho(\mathrm{r})$, for a series of halogenated molecules. This analysis clearly shows that for chlorine it is possible to observe an extended valence shell charge concentration (VSCC) region, containing either the charge concentration (CC) and charge depletion (CD) sites. On the other side, for bromine a far more reduced VSCC region is observed, containing only the CC sites, while the CD sites belong to a large region of positive $\nabla^{2} \rho(r)$ (which corresponds to a large portion of positive electrostatic potential) surrounding the bromine atom. This topology of $\nabla^{2} \rho(r)$ is in agreement with the positive values of the four lateral extra-point charges in the case of bromobenzene. Moreover, it can explain also the reason why the ' $5 \mathrm{~Pa}$ ' disposition is necessary for correctly describe chlorine halogen bonding: using only one extra-point charge linked to chlorine in the position of the $\sigma$-hole could induce an underestimation of the electrostatic charge related to the $\sigma$-hole (because of the extended VSSC region). By introducing the four lateral $\mathrm{Pa}(\mathrm{s})$, describing the "negative belt" of the halogen's ESP, the charge of the central Pa fits more accurately the real $\sigma$-hole charge derived from QM calculations.

The inadequacy of using only one extra-point charge to describe the anisotropy of the electrostatic potential around halogen atoms was pointed out also by Hage et al. ${ }^{35}$ In particular their observation on the requirement of the quadrupolar contribution to reproduce 
thermodynamic properties of halogen bonding (in particular for lighter halogens) by using hybrid (PC/MTP) approaches would help corroborate the '5 $\mathrm{Pa}$ ' model here proposed.

Table 2. Halogen bonding interaction distances and angles for the chlorobenzene-capped alanine dimer, computed with molecular mechanics using 0,1 and 5 pseudo-atoms and with M06-2X/6$311++\mathrm{G}(\mathrm{d}, \mathrm{p})$ geometry optimization. ${ }^{\mathrm{a}}$

\begin{tabular}{lll}
\hline Chlorobenzene & Distance/ $/$ & Angle ${ }^{\circ}$ \\
\hline No Pseudo-atom & Lost & Lost \\
1 Pseudo-atom & 3.02 & 169.97 \\
5 Pseudo-atoms & 3.24 & 161.14 \\
$\mathrm{M} 06-2 \mathrm{X} / 6-311++\mathrm{G}(\mathrm{d}, \mathrm{p})$ & 3.17 & 160.11 \\
\hline${ }^{\mathrm{a}} \mathrm{MM}$ calculations performed using $1.748 \AA$ as $\mathrm{VdW}$ parameter for the chlorine atom and $1.8 \AA$ \\
\multicolumn{2}{l}{ as $\mathrm{Pa}(\mathrm{s})$ distances from chlorine. }
\end{tabular}




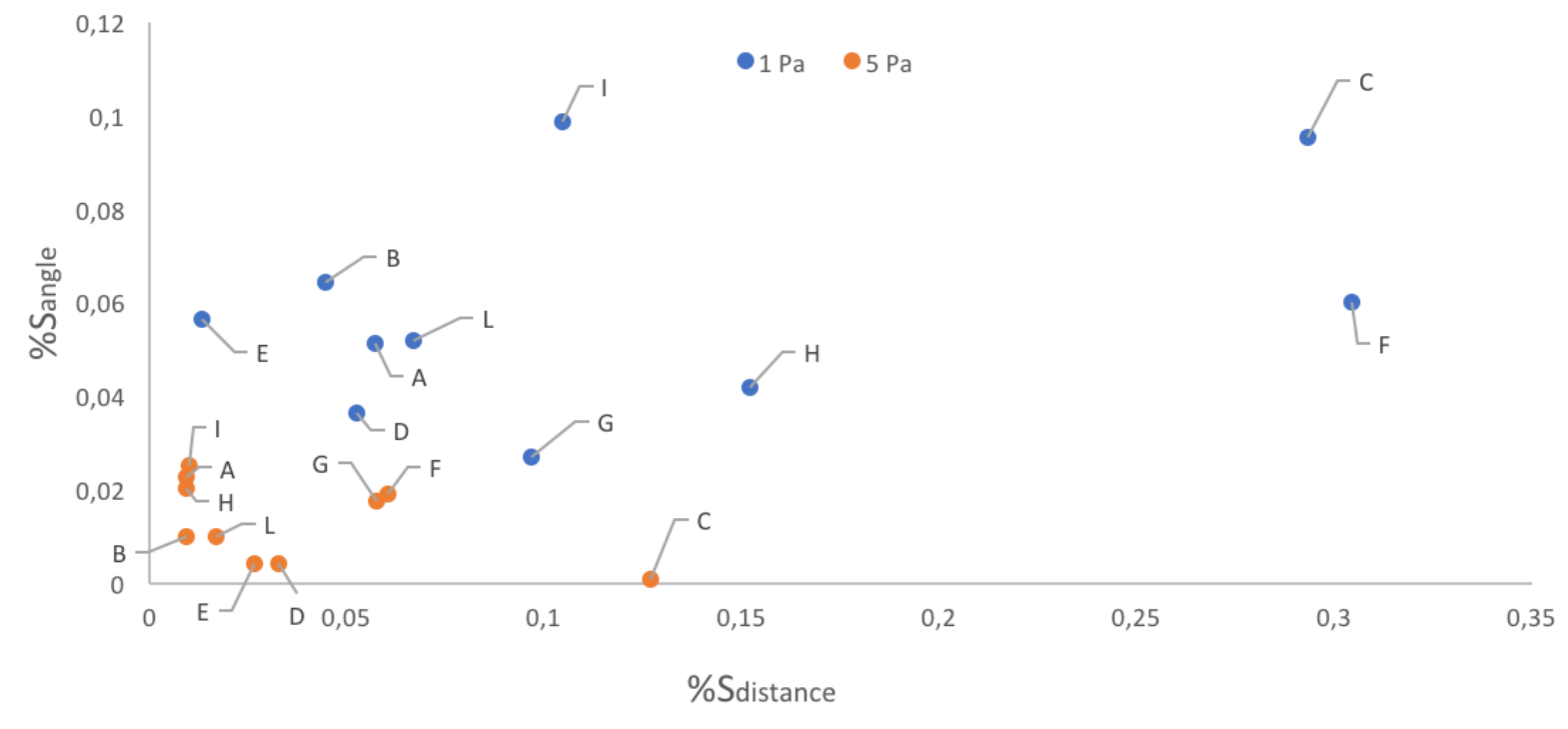

Figure 4. Percentage errors on halogen bonding distances (x-axis) and angles (y-axis), for the ten chlorinated systems studied in this work. '5Pa' strategy in red, ' $1 \mathrm{~Pa}$ ' strategy in blue (calculations performed using $1.748 \AA$ as vdW parameter for the chlorine atom and $2.0 \AA$ as $\mathrm{Pa}(\mathrm{s})$ distances from the central halogen).

Table 3. Selected RESP derived atomic point charges (in amu) in chlorobenzene: Carbon linked to chlorine, chlorine, pseudo-atom representing the $\sigma$-hole and the four lateral pseudo-atoms. 1.8 $\AA$ as $\mathrm{Pa}(\mathrm{s})$ distances from chlorine have been used.

\begin{tabular}{lccccccc}
\hline & $\mathrm{C}$ & $\mathrm{Cl}$ & $` \sigma$-hole’ Pa & $\mathrm{Pa}$ & $\mathrm{Pa}$ & $\mathrm{Pa}$ & $\mathrm{Pa}$ \\
\hline No Pa & -0.01 & -0.13 & - & - & - & - & - \\
$1 \mathrm{~Pa}$ & 0.02 & -0.15 & 0.01 & - & - & - & - \\
$5 \mathrm{~Pa}$ & 0.30 & -0.23 & 0.04 & -0.01 & -0.01 & -0.01 & -0.01 \\
\hline
\end{tabular}


Table 4. Selected RESP derived atomic point charges (in amu) in bromobenzene: Carbon linked to bromine, bromine, pseudo-atom representing the $\sigma$-hole and the four lateral pseudo-atoms. 1.8 $\AA$ as $\mathrm{Pa}(\mathrm{s})$ distances from chlorine have been used.

\begin{tabular}{|c|c|c|c|c|c|c|c|}
\hline & $\mathrm{C}$ & $\mathrm{Br}$ & ' $\sigma$-hole' $\mathrm{Pa}$ & $\mathrm{Pa}$ & $\mathrm{Pa}$ & $\mathrm{Pa}$ & $\mathrm{Pa}$ \\
\hline No Pa & -0.12 & -0.09 & - & - & - & - & - \\
\hline $1 \mathrm{~Pa}$ & 0.20 & -0.30 & 0.06 & - & - & - & - \\
\hline $5 \mathrm{~Pa}$ & 0.15 & -0.32 & 0.03 & 0.02 & 0.02 & 0.02 & 0.02 \\
\hline
\end{tabular}

For all studied systems, a decreasing of the RRMS error related to the RESP procedure has been observed passing from no to one and then to five Pa's. As pointed out in the previous pseudo-atoms studies for halogen bond, ${ }^{36-38}$ the introduction of an extra point charge linked to the halogen atom leads to an improvement of the description of the electrostatic potential around the halogens. The introduction of more than one Pa reduces only slightly the RRMS error, much less than what obtained passing from zero to one Pa. However, it is well known that small changes in the molecular electrostatic potential may involve even large variations in the chemistry of non-covalent interactions. Accordingly, the great improvement in the geometrical parameters of halogen bonded complexes observed upon insertion of more than one Pa derives from small modifications of the ESP, though they result in only limited improvement in the values the RRMS associated to the RESP procedure.

\section{CONCLUSIONS}

A series of chlorinated model systems have been studied by molecular mechanics energy minimization exploiting a set of extra-point charges to simulate the $\sigma$-hole and the negative belt 
characterizing the electron density distribution around the chlorine atom. Differently from the previously reported pseudo-atom (' $1 \mathrm{~Pa}$ ') approach, ${ }^{36-38}$ the ' $5 \mathrm{~Pa}$ ' strategy here proposed is demonstrated to well reproduce quantum mechanical geometrical parameters for halogen bonding interaction of the model systems with the carbonyl oxygen of the capped alanine. The model systems have been chosen to either reproduce real systems that are likely to be encountered in PDB and test the strategy to a rather extended range of XB strengths.

We found out that the MM description of chlorine XB has been greatly improved by the introduction of more than one Pa's in all the chlorinated model systems here investigated. This improvement is evident from the lowering of the percentage errors on the interaction distances and angles, as referred to benchmark M06-2X/6-311++G(d,p) geometry optimizations, when going from the ' $1 \mathrm{~Pa}$ ' to the ' $5 \mathrm{~Pa}$ ' methodology. The same improvement was not observed in the case of bromobenzene, suggesting the correctness of the ' $1 \mathrm{~Pa}$ ' strategy in the description of halogen bonding when bromine atoms are involved.

Moreover, it has been shown (through testing of different vdW radius values) that a reparametrization of the chlorine GAFF van der Waals radius should be taken into account to obtain a proper halogen bonding description.

Further development of this methodology will comprehend either testing our Pa's strategy on other model compounds (including different halogen bond acceptor) and performing molecular dynamic simulations on condensed phase systems (like complexes between proteins and chlorinated ligands).

\section{ASSOCIATED CONTENT}

\section{Supporting Information.}


Geometrical parameters (Tables $\mathrm{S} 1 \div \mathrm{S} 3$ ) and two-dimensional plots of the $S_{\text {angle }}$ and $S_{\text {distance }}$

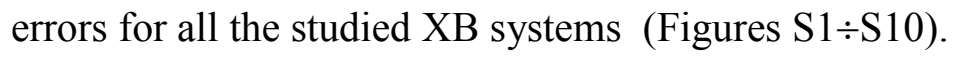

\title{
Author Contributions
}

The manuscript was written through contributions of all authors. All authors have given approval to the final version of the manuscript.

\section{ACKNOWLEDGEMENTS}

The Fondazione Banca del Monte di Lombardia is fully acknowledged for financial support.

\author{
ABBREVIATIONS \\ QM/MM, quantum mechanics/molecular mechanics; XB, halogen bonding; X, halogen; D, donor \\ group; A, acceptor group; ESP, electrostatic potential; HB, hydrogen bonding; PDB, protein data \\ bank; DFT, density functional theory; RESP, restrained electrostatic potential); Pa, pseudo-atom; \\ Pa's, pseudo-atoms; MM, molecular mechanics; GAFF, general AMBER force field; BSSE, \\ basis set superposition error; GGA, general gradient approximation; RRMS, root mean square \\ error; VdW, Van der Waals; VSCC, valence shell charge concentration; CC, charge \\ concentration; CD, charge depletion; QM, quantum mechanics; PC/MTP, point \\ charge/multipole.

\section{REFERENCES}

1. Clark, T; Hennemann, M; Murray, J. S.; Politzer, P. J. Mol. Mod., 2007, 13, 291-296.

2. Politzer, P.; Murray, J. S. Crystals 2017, 7, 212.

3. Riley, K. E.; Murray, J. S.; Politzer, P; Concha, M. C.; Hobza, P. J. Chem. Theory Comput. 2009, 5, 155. 
4. Riley, K. E.; Murray, J. S.; Fanfrlik, J.; Řezáč, J.; Solà, R. J.; Concha, M. C.; Ramos, F. M.; Politzer, P. J. Mol. Model. 2011, 17, 3309.

5. Lu, Y.; Zou, J.; Wang, Y.; Jiang, Y.; Yu, Q. J. Phys. Chem. A, 2007, 111, 42, 1078110788.

6. Forni, A.; Lucenti, E.; Botta, C.; Cariati, E. J. Mater. Chem. C 2018, 6, 4603-4626.

7. Cariati, E.; Cavallo, G.; Forni, A.; Leem, G.; Metrangolo, P.; Meyer, F.; Pilati, T.; Resnati, G.; Righetto, S.; Terraneo, G.; Tordin, E. Cryst. Growth Des. 2011, 11, 12, $5642-5648$.

8. Thallapally, P. K. ; Desiraju, G. R. ; Bagieu-Beucher, M. ; Masse, R. ; Bourgogne, C. ; Nicoud, J. Chem. Commun. 2002, 1052-1053.

9. Christodoulou, M. S.; Zunino, F.; Zuco, V.; Borrelli, S.; Comi, D.; Fontana, G.; Martinelli, M.; Lorens, J. B.; Evensen, L.; Sironi, M.; Pieraccini, S.; Via, L. D.; Gia, O. M.; Passarella, D. Chem. Med. Chem., 2012, 7, 2134-2143.

10. Voth, R.; Hays, F. A.; Ho, P. S. Proc. Natl. Acad. Sci., U. S. A. 2007, 104, 15, $6188-6193$.

11. Hardegger, L. A.; Kuhn, B.; Spinnler, B.; Anselm, L.; Ecabert, R.; Stihle, M.; Gsell, B.; Thoma, R.; Diez, J.; Benz, J.; Plancher, J.; Hartmann, G.; Banner, D. W.; Haap, W.; Diederich, F.; Angewandte Chemie, 2010, 50, 1, 314-318.

12. Christodoulou, M. S.; Calogero, F.; Baumann, M.; García-Argáez, A. N.; Pieraccini, S.; Sironi, M.; Dapiaggi, F.; Bucci, R.; Broggini, G.; Gazzola, S.; Liekens, S.; Silvani, A.; 
Lahtela-Kakkonen, M.; Martinet, N.; Nonell-Canals, A.; Santamaría-Navarro, E.; Baxendale, I. R.; Dalla Via, L.; Passarella, D. Eur. J. Med. Chem. 2015, 92, 766-775.

13. Ho, P. S. Future Med. Chem. 2017, 9, 637-640.

14. Christodoulou, M. S.; Sacchetti, A.; Ronchetti V.; Caufin, S. A.; Silvani, A.; Lesma G.; Fontana, G.; Minicone, F.; Riva, B.; Ventura, M.; Lahtela-Kakkonen, M; Jarho, E.; Zuco, V.; Zunino, F.; Martinet, N.; Dapiaggi, F.; Pieraccini, S.; Sironi, M.; Dalla Via, L.; Gia, O. M.; Passarella, D. Bioorganic Med. Chem., 2013, 21, 6920-6928.

15. Rowe, R. K.; Ho, P. S. Acta Cryst. B, 2017, B73, 255-264.

16. Carlsson, A. C.; Scholfield, M. R.; Rowe, R. K.; Ford, M. C.; Alexander, A. T.; Mehl, R. A.; Ho, P. S. Biochemistry, 2018, 57, 4135-4147.

17. Hardegger, L. A.; Kuhn B.; Spinnler, B.; Anselm, L.; Ecabert, R.; Stihle, M.; Gsell, B.; Thoma, R.; Diez, J.; Benz, J.; Plancher, J. M.; Hartmann, G.; Isshiki, Y.; Morikami, K.; Shimma, N.; Haap, W.; Banner, D. W.; Diederich, F. Chem. Med. Chem., 2016, 6, 20482054.

18. Lu, Y.; Shi T.; Wang Y.; Yang, H.; Yan, X.; Luo, X.; Jiang, H.; Zhu, W. J. Med. Chem. 2009, 52, 2854-2862.

19. Forni, A.; Pieraccini, S.; Rendine, S.; Sironi, M. J. Comp. Chem. 2014, 35, 386.

20. Forni, A.; Pieraccini, S.; Rendine, S.; Gabas, F.; Sironi, M. ChemPhysChem 2012, 13, 4224.

21. Forni, A.; Pieraccini, S.; Franchini, D.; Sironi, M. J. Phys. Chem. A 2016, 120, 9071. 
22. Kozuch, S.; Martin, J. M. L. J. Chem. Theory Comput., 2013, 9, 1918.

23. Lu, Y.; Li, H.; Zhu, X.; Zhu, W.; Liu, H. J. Phys. Chem. A 2011, 115, 4467.

24. Lu, Y.; Li, H.; Zhu, X.; Liu, H.; Zhu, W. Int. J. Quantum Chem. 2012, 112, 1421.

25. Forni, A.; Rendine, S.; Pieraccini, S.; Sironi, M. J. Mol. Graph. Model. 2012, 38, 31.

26. Cornell, W. D.; Cieplak, P.; Bayly C. I.; Kolman, P. A. J. Am. Chem. Soc. 1993, 115, $9620-9631$.

27. Ford, M. C.; Ho, P. S. J. Med. Chem., 2017, 60, 8681-8690.

28. Hage, K. E.; Bereau, T.; Jakobsen, S.; Meuwly, M. J. Chem. Theory Comput. 2016, 12, 7, 3008-3019.

29. Jorgensen, W. L.; Schyman, P. J. Chem. Theory Comput. 2012, 8, 10, 3895-3901.

30. Harder, E.; Damm, W.; Maple, J.; Wu, C.; Reboul, M.; Xiang, J. Y.; Wang, L.; Lupyan, D.; Dahlgren, M. K.; Knight, J. L.; Kaus, J. W.; Cerutti, D. S.; Krilov, G.; Jorgensen, W. L.; Abel, R.; Friesner, R. A. J. Chem. Theory Comput 2016 12, 1, 281-296.

31. Mu, X.; Wang, Q.; Wang, L. P.; Fried, S. D.; Piquemal, J. P.; Dalby, K. N.; Ren, P. J. Phys. Chem. B 2014 118, 24, 6456-6465.

32. Gutiérrez, I. S.; Lin, F. Y; Vanommeslaeghe, K.; Lemkul, J. A.; Armacost, K. A.; Brooks, C. L.; MacKerell Jr, A. D. Bioorg. Med. Chem. 2016, 24, 4812-4825. 
33. Ho, P. S. In: Metrangolo P.; Resnati G., Halogen Bonding I. Topics in Current Chemistry, vol. 358., 2015, Springer, Cham. (Pages 241-276).

34. Scholfield, M. R.; Ford, M. C.; Vander Zanden, C. M.; Billman, M. M.; Ho, P. S.; Rappé, A. K. J. Phys. Chem. B 2015, 119, 29, 9140-9149.

35. Santos, L. A.; da Cunha, E. F. F.; Ramalho, T. C. J. Phys. Chem. A 2017, 121, 2442

36. Kolár, M.; Hobza, P. J. Chem. Theory Comput. 2012, 8, 4, 1325-1333.

37. Ibrahim, M. A. A. J. Chem. Theory Comput. 2011, 32, 12, 2564-2574.

38. Rendine, S.; Pieraccini, S.; Forni, A.; Sironi, M. Phys. Chem. Chem. Phys. 2011, 13, 43, 19508-19516.

39. Auffinger, P.; Hays, F. A.; Westhof, E.; Ho, P. S. PNAS 2004, 101, 48, 16789-16794.

40. Eskandari, K.; Lesani, M. Chem. Eur. J. 2015, 21, 1-9.

41. Lin, F. Y.; MacKerrell, A. D.; J. Chem. Theory Comput. 2018, 14, 2, 1083-1098.

42. Lin, F. Y.; MacKerrell, A. D. J Phys. Chem. B 2017, 121, 28, 6813-6821.

43. Wilcken, R.; Zimmermann, M. O.; Lange, A.; Joerger, A. C.; Boeckler, F. M. 2013, J. Med. Chem. 2013, 56, 4, 1363-1388.

44. Zhao, Y.; Truhlar, D. G. Theor. Chem. Acc. 2008, 120, 1-3, 215-241.

45. Özpınar, G. A.; Peukert, W.; Clark T. J Mol Model 2010, 16, 1427-1440.

46. Frisch, M. J.; Trucks, G. W.; Schlegel, H. B.; Scuseria, G. E.; Robb, M. A.; Cheeseman, J. R.; Scalmani, G.; Barone, V.; Mennucci, B.; Petersson, G. A.; Nakatsuji, H.; Caricato, 
M.; Li, X.; Hratchian, H. P.; Izmaylov, A. F.; Bloino, J.; Zheng, G.; Sonnenberg, J. L.; Hada, M.; Ehara, M.; Toyota, K.; Fukuda, R.; Hasegawa, J.; Ishida, M.; Nakajima, T.; Honda, Y.; Kitao, O.; Nakai, H.; Vreven, T.; Montgomery, J. A., Jr.; Peralta, J. E.; Ogliaro, F.; Bearpark, M.; Heyd, J. J.; Brothers, E.; Kudin, K. N.; Staroverov, V. N.; Kobayashi, R.; Normand, J.; Raghavachari, K.; Rendell, A.; Burant, J. C.; Iyengar, S. S.; Tomasi, J.; Cossi, M.; Rega, N.; Millam, J. M.; Klene, M.; Knox, J. E.; Cross, J. B.; Bakken, V.; Adamo, C.; Jaramillo, J.; Gomperts, R.; Stratmann, R. E.; Yazyev, O.; Austin, A. J.; Cammi, R.; Pomelli, C.; Ochterski, J. W.; Martin, R. L.; Morokuma, K.; Zakrzewski, V. G.; Voth, G. A.; Salvador, P.; Dannenberg, J. J.; Dapprich, S.; Daniels, A. D.; Farkas, Ö.; Foresman, J. B.; Ortiz, J. V.; Cioslowski, J.; Fox, D. J. Gaussian 09, Revision D.01 Gaussian, Inc., Wallingford CT, 2013.

47. Wang, J.; Wolf, R. M.; Caldwell, J. W.; Kollman P. A.; Case, D. A. J. Comput. Chem. 2004, 25, 1157-1174.

48. Lindorff-Larsen, K.; Piana, S.; Palmo, K.; Maragakis, P.; Klepeis, J. L.; Dror R.O.; Shaw, D. E. Proteins 2010, 78, 1950.

49. Abraham, M. J.; Murtola, T.; Schulz, R.; Pall, S.; Smith, J. C.; Hess, B.; Lindahl, E. SoftwareX, 2015, 1-2 19-25.

50. Brezgunova, M. E.; Aubert, E.; Dahaoui, S.; Fertey, P.; Lebègue, S.; Jelsch, C.; Ángyán, G. J.; Espinosa, E. Cryst. Growth Des. 2012, 12, 11, 5373-5386. 